\title{
Andarilhos de estrada: estudo das motivações e da vivência das injunções características da errância ${ }^{1}$
}

\author{
Rodrigo Sanches Peres ${ }^{2}$
}

\begin{abstract}
Resumo
A presença de andarilhos de estrada é cada vez mais notável nos acostamentos das rodovias brasileiras. O presente trabalho teve como objetivo investigar os eventos que levaram esses indivíduos a abandonar os referenciais da vida em sociedade e analisar a forma como são vivenciadas as injunções características desse modo de existência. Foram tomados como sujeitos quinze andarilhos de estrada albergados em uma instituição assistencial da cidade de São Carlos (SP) e realizadas entrevistas semi-estruturadas, que foram gravadas, transcritas na íntegra e submetidas a uma análise de conteúdo. Os diversos fatores apontados como motivadores do nomadismo foram categorizados em dois planos: psicológico e socioeconômico. A vida no "trecho" é permeada por um sentimento constante de incerteza e insegurança, decorrente da precariedade e do isolamento característicos dessa condição.

Palavras-chave: Andarilhos de estrada; alcoolismo; desemprego; conflitos afetivos-familiares.
\end{abstract}

Highway wanderers: a study on the motivations and the characteristic injunctions of wandering

\begin{abstract}
The presence of wanderers in highways is conspicuous. The aim of the present paper is to inquiry into the events that lead to abandon the social life referentials and analyse the means by which the characteristic injunctions affect these people. Fifteen highway wanderers subjects were taken up for this survey who were at a social institution in São Carlos. We recorded semistructured interviews which were later transcribed and submitted to a content analysis. Several factors pointed out as motivators of the nomadism were classified in two plans: psychological and social-economic. The instability and isolation are peculiar to such a condition, and life is considered precarious and security something beyond reach.

Keywords: highway wanderers; alcoholism; unemployment; affective familiar conflicts.
\end{abstract}

\section{Introdução}

Nos dias de hoje, a chamada "globalização" provoca mudanças sociais, econômicas e políticas que levam cada vez mais a um rompimento com os espaços sociais fechados, a um desenraizamento que exige grande mobilidade psicológica a fim de permitir uma rápida reorientação de identificações, comportamentos, sentimentos e relacionamentos. Esse mundo em constante transformação reacende os movimentos de andança humana, protagonizados por indivíduos que rompem com a acomodação, motivados pelo desejo de encontrar um lugar melhor (Justo, 1998).

Sob a égide da economia globalizada da atualidade, é notável a presença cada vez mais maciça de andarilhos de estrada e/ou "trecheiros" nas rodovias brasileiras. São sujeitos que vivem nos acostamentos de autoestradas, caminhando solitária e compassadamente sem destino, carregando num saco ou mochila puída todos os seus pertences. Segundo a tipologia dos moradores de rua proposta por Snow e Anderson (1998), os andarilhos de estrada podem ser classificados como

\footnotetext{
1 Trabalho subvencionado pelo CNPq e orientado pelo Dr. José Sterza Justo, do Departamento de Psicologia Social, Evolutiva e Escolar da UNESP/ Assis

${ }^{1}$ Endereço para correspondência:

Rua Jesuíno de Arruda, 2753 - Centro, São Carlos - SP , 13560-060.

E-mail: rodrigo_sanches_peres@hotmail.com
}

outsiders, pois este termo se refere “...à condição de estar permanentemente e por imputação colocado fora das disposições estruturais de um dado sistema social, ou de estar situacional ou temporariamente excluído, ou de voluntariamente se excluir do comportamento de membros que têm status e função dentro daquele sistema" (Turner, 1974, apud Snow \& Anderson, 1998, p. 101). O conceito de outsider é bastante abrangente, de modo que entre os membros desse grupo podem-se observar diferenças importantes. Assim sendo, os andarilhos formam um subgrupo que possui certas peculiaridades: são altamente migratórios, utilizam bebidas alcoólicas diariamente e em grandes doses, adotam como meio de subsistência basicamente a mendicância $\mathrm{e} / \mathrm{ou}$ eventuais trabalhos temporários $\mathrm{e}$ parecem ter-se conformado com a vida na rua, devido principalmente à falta de perspectivas.

A maioria dos "trecheiros" caminha desacompanhada, desconfia das pessoas que procuram uma aproximação e busca o "outro" apenas em situações de necessidade extrema. Tais características parecem estar intimamente vinculadas com a deserção social, que se desdobra em estreitamento da socialidade e restrição dos relacionamentos pessoais. $\mathrm{O}$ andarilho, segundo Justo (1998), pode ser considerado, numa analogia metafórica, uma caricatura do homem da atualidade, com seus traços principais acentuados: a exigência de 
constante movimentação profissional, afetiva, social, política e econômica torna-o um indivíduo sem ancoragens fixas, incessantemente desejante.

A errância gera uma revisão e alteração de crenças, valores, representações mentais e "esquemas de sobrevivência construídos em função da adaptação a uma realidade relativamente estável dada pela fixação do sujeito a um determinado lugar" (Justo, 1998, p. 126). A ruptura com os referenciais que dão estabilidade e segurança a uma pessoa, como a família, o trabalho, os amigos, assim como o rompimento com a rede social e a impossibilidade de se estabelecer qualquer espécie de vínculo duradouro faz com que a errância do andarilho seja uma das mais intensas possíveis.

Em suma, pode-se pensar na errância como um fenômeno complexo, multifatorial, que parece ter como principal mola propulsora uma realidade social em transformação contínua e que exige uma readaptação incessante a novos paradigmas. Entretanto, para evitar uma abordagem reducionista desta questão, há ainda que se problematizar o conceito tradicional de errância. Nesta passagem de século, a globalização implementa um pouco de errância em cada um de nós, por mais vinculados que estejamos a referenciais estáveis. Conforme Justo (1998), no mundo atual o imperativo do movimento não nos permite mais ficar parados em um só lugar; estamos constantemente em movimentação, mesmo que sentados defronte à tela de um computador, navegando na internet.

\section{Errância e alcoolismo}

O álcool, conforme Snow e Anderson (1998, p.81), é um dos "traços definidores centrais da subcultura dos homens moradores de rua", a despeito dos diversos comprometimentos - físicos, psíquicos, sociais, familiares e profissionais - inerentes à intoxicação etílica (Castro \& Silva Filho, 1993). A grande maioria dos andarilhos ingere diariamente doses consideráveis de bebidas alcoólicas, notadamente "pinga" ou "cachaça", o que permite caracterizá-los como alcoólicos crônicos, segundo a definição de Sonenreich (1971).

Diversos trabalhos com populações errantes demonstram que a ingestão de bebidas alcoólicas está intimamente ligada a uma necessidade premente de esquecer as dificuldades da vida, relacionadas tanto às frustrações e fracassos do passado quanto às condições adversas e à realidade sombria do presente, e ainda à falta de perspectivas promissoras para o futuro - que leva a uma anulação quase total de aspirações e à desesperança. $\mathrm{O}$ álcool representaria uma possibilidade de evasão dessa difícil realidade, trazendo certo alívio e tranqüilidade, ainda que por um breve momento. Além disso, o consumo etílico abusivo parece intrinsecamente associado à gênese do rompimento com os referenciais da vida social, conduzindo, indiretamente à deserção e à errância (Nascimento, 1999; Justo, 1998; Snow \& Anderson, 1998; Nascimento \& Justo, 2000).

\section{A causalidade múltipla da errância}

Para que se possa compreender a errância em seus diversos aspectos é preciso que se atente para a intrincada multifatorialidade característica desse complexo fenômeno. Faz-se necessário um exame de cada um dos fatores que podem atuar como motivadores da ruptura com as malhas da rede social e que se procure estabelecer as co-relações e articulações entre os mesmos.

A economia globalizada do mundo capitalista contemporâneo leva, em última instância, à precarização das relações de trabalho e ao desemprego, gerando o aumento da vulnerabilidade social, a desfiliação, a segregação, a pobreza e a exclusão social (Castel, 1998). O sujeito desempregado, por não conseguir acompanhar a dinâmica da sociedade capitalista salarial e nem tampouco se inscrever nas coerções da atual conjuntura econômica, passa a ser visto como um "inadaptado social". A falta de um emprego e a decorrente ausência de reconhecimento social causa experiências de sofrimento, associadas à segregação e à exclusão (Jacques, 1998), de tal maneira que a vida pessoal desses indivíduos entra em crise, o que leva muitos deles a se agregarem aos que vagam pelas ruas, sem teto e sem vínculos sociais estáveis (Singer, 1999). Dessa forma, as mudanças sociais, políticas e econômicas do mundo na atualidade criam uma classe cada vez maior de miseráveis e contribuem para o crescimento do movimento de errantes e andarilhos.

Conflitos e desavenças familiares, tanto com os pais no núcleo familiar originário, quanto com a esposa e filhos, são fatores preponderantes para a ruptura do sujeito com o nicho social no qual está inserido (Snow \& Anderson, 1998). A ausência de uma constelação familiar continente, os desentendimentos com os genitores e os conflitos afetivos decorrentes de relacionamentos amorosos que tiveram um final desestruturante em virtude de traições e/ou infidelidade conjugal são acontecimentos perturbadores (Pittman, 1994) que, atuando em conjunto com outras motivações igualmente intensas, podem levar um sujeito a romper com as malhas da rede social. A decisão de "correr o trecho" em muitos casos emerge como uma resposta radical e extremada a esses conflitos. Pode-se supor ainda que, na realidade, esses laços se rompem ante determinadas dificuldades apenas em razão das circunstâncias sociais precárias em que se formaram e vinham se mantendo, dando a tais vínculos um aspecto frágil e pouco vigoroso. 
De qualquer modo, abandonar os referenciais sociais que norteiam a vida no mundo atual e as fixações sociais, geográficas e afetivas é uma atitude drástica, tendo em vista as dificuldades que são instaladas com a errância. Por isso acredita-se que nenhum evento isolado, por mais desestruturante que seja, leva, por si só, uma pessoa à condição de nômade errante. Tudo indica que, na maioria absoluta dos casos, há uma interação dos diversos fatores que concorrem para a deserção. O que parece inquestionável é que todos esses fatores estão intimamente ligados a algumas das principais características que modelam o mundo contemporâneo.

\section{Objetivos}

O presente trabalho teve como objetivos principais: a) investigar a história de vida dos andarilhos de estrada; b) detectar as motivações que levaram estes sujeitos à atual condição de vida; e c) analisar a forma como são vivenciadas as injunções características desse modo de existência no cotidiano no "trecho".

\section{Métodos}

\section{Sujeitos}

Foram tomados como sujeitos da presente pesquisa quinze (15) andarilhos de estrada, todos do sexo masculino, que fazem uso de bebidas alcoólicas e não possuem residência fixa. A faixa etária dos entrevistados variou de 25 a 58 anos, e o tempo no "trecho" de 3 a 40 anos.

Os dados foram coletados junto ao Serviço de Obras Sociais - Albergue Noturno "São Vicente de Paula", na cidade de São Carlos (SP). As entrevistas foram realizadas individualmente, em sala apropriada, respeitando as condições adequadas para a situação e em conformidade com a Resolução no 196/96, do Ministério da Saúde, sobre pesquisas envolvendo seres humanos. A aplicação das entrevistas durou, em média, aproximadamente 40 minutos.

\section{Instrumentos e procedimentos}

Utilizou-se uma entrevista semi-estruturada composta por uma seqüência de questões que introduz gradualmente os sujeitos nos assuntos que, teoricamente, possuem maior implicação afetiva. $\mathrm{O}$ roteiro da entrevista foi dividido em quatro tópicos:

Tópico 1 - História de vida. O objetivo deste tópico é investigar a história de vida dos sujeitos, procurando conhecer aspectos do relacionamento familiar desde a infância até a idade adulta e os acontecimentos marcantes da trajetória desses indivíduos.

Tópico 2 - Processos de ruptura e vida no "trecho". Este tópico tem como meta delinear os motivos que levaram o sujeito a romper com os vínculos estáveis da rede social e a isolar-se no "trecho", investigando o modo de vida antes e depois da deserção, assim como suas estratégias de sobrevivência, seus relacionamentos sócio-afetivos, os vínculos e as regras estabelecidas no "trecho" e as vantagens e desvantagens desse modo de existência.

Tópico 3 - Uso do álcool. O propósito deste tópico é investigar as influências que levaram os sujeitos ao alcoolismo e os motivos que ainda perpetuam esse hábito, que é um dos traços definidores do estilo de vida dos andarilhos.

Tópico 4 - Relaçoes afetivas. Este tópico tem por finalidade conhecer as relações afetivas dos sujeitos, investigando a ocorrência de desilusões amorosas, traição, infidelidade e ciúme.

Mediante o consentimento prévio dos sujeitos, as entrevistas foram gravadas, transcritas na íntegra e submetidas a uma análise de conteúdo, conforme a proposta de Bardin (1979). Foi ainda organizada uma estrutura condensada das informações, possibilitando confrontos e discussões com o referencial teórico encontrado na literatura específica e elaborado um conjunto de generalizações que abrangem a consistência dos dados apresentados.

\section{Resultados}

Os resultados a serem apresentados foram divididos em quatro tópicos, de acordo com a estrutura elaborada para o roteiro das entrevistas. Os temas emergentes em cada tópico serão agrupados em categorias e subcategorias, organizadas segundo as unidades de sentido que puderam ser identificadas.

No Tópico 1 (História de vida), os temas foram agrupados em duas categorias: a) vida na infância e adolescência e b) relacionamento familiar.

$V i d a$ na Infância e Adolescência. Os sujeitos fazem uma leitura sobre os acontecimentos referentes a esse período que pode ser analisada em duas subcategorias:

-vida satisfatória. Apenas quatro andarilhos (26,6\%) relataram que a vida foi satisfatória em sua infância e adolescência, como exemplifica a seguinte fala:

"É, uma vida normal. Estudei o primário, morava com a minha familia" (E 6).

-vida insatisfatória. Para 73,4\% dos sujeitos (onze andarilhos), a infância e adolescência foram períodos difíceis, dos quais guardam lembranças dolorosas e desagradáveis. Por exemplo:

"Olha, moço. Pra falá a verdade, en não tive infância, não. Nem infância, sinceramente, eu não tive. Acabaram com a minha infância” (E 14).

Relacionamento Familiar. Apenas quatro andarilhos (26,6 \%) afirmaram que seus relacionamentos com os

Psico-USF, v.6, n.1, p.67-75, jan./jun. 2001 
familiares eram satisfatórios. Por outro lado, onze sujeitos $(73,4 \%)$ relataram que a vivência em família foi marcada por desavenças e conflitos. Dessa forma, esse tema pode ser subdividido em duas subcategorias:

-relações satisfatórias. O depoimento dos sujeitos que consideram que seus relacionamentos familiares foram satisfatórios foi dado com pouquíssima ou nenhuma convicção, de modo que nesses casos provavelmente estava sendo utilizada a negação como mecanismo de defesa. Exemplo:

"Bom. Alegre, né?" (E 7).

- relaçoes insatisfatórias. As desavenças com os pais foram constantes para a maior parte dos entrevistados, como se pode perceber pela seguinte fala:

"Pai eu nunca tive...Minha mãe só me deu porrada. Só, só isso" (E 14).

Os temas emergentes no Tópico 2 (Processos de ruptura e vida no "trecho") permitiram a identificação dos principais eventos motivadores do rompimento com as malhas da rede social, da forma como são vivenciadas as injunções características desse modo de existência e da maneira como o cotidiano é instável e incerto para a maioria dos "trecheiros". Este tópico será dividido em 6 categorias:

Motivos da Iniciação no "Trecho". Os fatores associados, segundo o relato dos sujeitos, à iniciação no "trecho" podem ser divididos em duas subcategorias. Vale ressaltar que tais categorias não são mutuamente exclusivas, visto que a deserção geralmente é causada por uma intrincada rede de eventos motivadores:

-fatores psicológicos. As desavenças com os pais e os desentendimentos familiares - com esposa e filhos foram, assim como os relacionamentos afetivos malsucedidos, apontados por treze andarilhos (86,6 \%) como eventos motivadores da ruptura com a vida sedentária, como comprovam as seguintes verbalizações:

"Eu decidi pegar a estrada, camarada, porque chegou um ponto que os cara não queria eu lá em casa” (E 4).

"Casei... com uma menina dez anos mais nova que eu. Vivi doze anos com ela, criei um filho que eu peguei com três anos, criei até os quinze. Isso faz quatro anos atrás. Dai eu larguei, não deu mais certo... e en fiquei sozinho, resolvi correr o trecho" (E 9).

Segundo o relato de oito andarilhos (53,3\%), a morte dos pais foi um fator preponderante para a iniciação no "trecho", não só pela perda dos referenciais sociais, emocionais e afetivos que são inerentes a um núcleo familiar capaz de oferecer um mínimo de continência, mas também por ser um evento que traz, como desdobramento indireto, o desamparo financeiro, o desabrigo e o aumento da pauperização. Exemplo:

"É que morreu o pai, a mãe, né? Ai caí na estrada" (E 5).

-fatores socioeconômicos. A falta de um emprego motivada principalmente pela baixa qualificação profissional dos entrevistados e pelas profundas modificações que a conjuntura do trabalho sofreu nas últimas décadas, implantando a tendência da intelectualização do trabalho decorrente do avanço científico e tecnológico que se observa na sociedade atual - também atuou como uma das forças mais operantes do processo de deserção, segundo o depoimento de oito andarilhos (53,3\%). O "trecho" era visto, no início, como uma saída paliativa radical para o desemprego e o conseqüente e inevitável processo de empobrecimento. Exemplo:

'É... o desemprego tá muito grande no Ceará, Fortaleza, o desemprego tá cada vez crescendo e os governo não tão mais ajudando como era antigamente. Aqui em São Paulo, já faz nove mês que eu tô aqui, também tá difícil" (E 10).

Regras de Conduta. Ao serem indagados sobre a existência de alguma espécie de "lei" ou "regra informal" entre os andarilhos, nove deles (60\%) afirmaram que cada sujeito pauta sua conduta de acordo com seus próprios valores individuais. Certas características, como a honestidade, o companheirismo e o desprendimento para compartilhar alimentos, roupas ou mesmo informações, são valorizadas, mas a individualidade parece ser a única "lei". Exemplos:

"Regra? Eu acho que... acho que não... Não tem isso não. Você entendeu, né? É cada um por si...” (E 12).

Subsistência no "Trecho". Onze andarilhos (73,3\%) afirmaram que a mendicância é o meio adotado para garantir a sobrevivência no "trecho". Entretanto, quatro deles $(26,7 \%)$ relataram que utilizam esse recurso somente em último caso, pois preferem sobreviver às custas de eventuais trabalhos temporários. Quando estão na estrada costumam procurar para descansar à noite postos de combustível ou terrenos descampados adjacentes ao acostamento das rodovias Nas cidades, os "trecheiros" geralmente procuram albergues e/ou outras instituições assistenciais que oferecem pernoite, refeições e também eventualmente cedem roupas e "passes" de ônibus. Dessa forma, percebe-se o quanto é precária essa condição, como exemplificam os seguintes relatos:

"Se você tiver na cidade, você pede nas casa. Se você tiver andando na estrada você pede nos posto" (E 5).

"... eu durmo no mato, no posto, na estrada" (E 6).

Estilo de Vida. A evasão para o "trecho" obviamente traz transformações profundas na vida dos andarilhos, levando-se em conta as diferenças determinantes que existem entre o sedentarismo e o nomadismo. Dessa forma, essa categoria pode ser dividida em duas subcategorias:

-vida antes do "trecho". Antes de começarem a "correr o trecho", os sujeitos levavam uma vida norteada por valores minimamente estáveis, tais como o trabalho (seja fixo, sazonal ou volante), uma residência social e a 
inserção em um núcleo familiar, com os pais ou esposa e filhos. A vida anterior à deserção foi considerada satisfatória e razoável por onze indivíduos (73,3\%), apesar da existência de algumas dificuldades. Por exemplo:

"Olha, a de antes era melhor... ficava num lugar só, trabalhava" (E 12)

-vida depois do "trecho". A insuportabilidade da errância, decorrente principalmente do desamparo social, da precariedade e desassistência com as quais os andarilhos convivem diariamente, pode ser percebida nas seguintes falas, que evidenciam que a vida sedentária era, para quatorze dos entrevistados (93,3\%), muito melhor do que a vida atual:

"Não tem nenbuma vantagem. É só bumilhação. Ser bumilhado. Nenhum homem gosta. Mandam você trabalhá, chamam você de vários nomes e você é um cara do trabalho. A maioria, 99\% qué trabalhá. Às vežes não consegue, pede uma ajuda pra não morrê de fome. O cara te chama de vagabundo, safado, sem-vergonha. Muitos tacam a faca" (E 6).

Vantagens e Desvantagens do "Trecho". Apenas três sujeitos $(20 \%)$ apontaram a existência de alguma vantagem ou condição favorável relacionada ao fato de estar no "trecho". Para o restante dos entrevistados (doze deles, ou seja, 80 \%), a errância oferece apenas desvantagens. Dessa forma, emergem dessa categoria duas subcategorias distintas:

-pontos positivos. A aparente liberdade oferecida pelo "trecho" parece ser reconhecida como a única vantagem associada a esta condição de vida.

“(a vantagem) é a sensação de tá livre, de ser livre...” (E 9).

-pontos negativos: A precariedade, a desassistência e a provisoriedade que permeiam a errância em todos os aspectos são vistas como suas maiores desvantagens.

"Desvantagem é 100\%, porque você tá indefeso. Hoje você come aqui, né? Amanhã você nem sabe se vai comê" (E 8).

Perspectivas e Aspirações Futuras. O desejo de voltar à vida sedentária, reconstituir família e readquirir um emprego e uma residência fixa parecem ser os maiores sonhos dos entrevistados, de acordo com quatorze deles (93,3\%). No entanto, poucos acreditam nesse retorno:

"Meu objetivo é vencer... é uma casa pra morar, ter uma família pra criar, mas eu fiquei na mão...” (E 1).

"Ter, eu até tenho. Mas eu não tenho como voltá, né? Eu tô nessa vida não porque eu queira, entende?" (E 8).

No Tópico 3 (Uso do álcool) será feita uma divisão dos temas em 4 categorias:

Início do Uso de Bebidas Alcoólicas. Segundo o relato de onze entrevistados $(73,3 \%)$, as primeiras experiências com a bebida ocorreram por volta dos sete aos quinze anos de idade. Foram citadas como principais influências para tanto o grupo de amigos e familiares próximos:

"Eu tinha 12 anos... Ah, o primeiro contato foi na escola.
Ah, compraram lá um litrão e eu tomei, né?" (E 1).

"Eu aprendi a beber com a minha avó, a mãe do meu padrasto. Ela mandava eu buscar meia garrafinha de pinga, eu ia correndo. Ai ela bebia, deixava um golinho na xicara de louca e falava: Quer um golinho? Dai eu tomava um golinho, podia bebê com ela. Dai depois que ela esquecia a garrafa, ai eu ia lá e tomava um golão" (E 2).

Início do Uso Abusivo do Álcool. Apesar de terem provado bebidas alcoólicas pela primeira vez na infância ou no início da adolescência, doze andarilhos (80\%) afirmaram que o uso abusivo efetivou-se na idade adulta. Tais sujeitos identificam basicamente dois eventos disparadores do consumo excessivo: a iniciação no "trecho" e/ou a morte dos pais:

"... o que mais me levou a beber é que en fiquei meio desgostoso da vida de eu ter perdido minha mãe... por causa de que eu amava muito ela. Ai de repente aconteceu o desastre, né?" (E 1).

"Eu sempre tive alguns colega que bebia, a gente saía junto $e$ coisa e tal... en bebia socialmente assim, cerveja, uma coisinha assim, à toa... pra bebê, bebê mesmo assim eu comecei depois que eu sai pro trecho. As vezes no trecho a gente tem que bebê um pouquinho" (E 14).

Motivos do Uso do Álcool no "Trecho". Dez andarilhos (66,6 \%) apresentaram em seus relatos uma associação direta entre a bebida e a necessidade de esquecer frustrações do passado e presente, principalmente relacionadas à morte dos pais e à precariedade característica do nomadismo:

"Se eu não bebo alguma coisa me faz sentir infeliz. Tá faltando alguma coisa, a bebida completa um lado. Então eu bebo pra me sentir feliz e esquecer um lado men que en quero esquecer. Talvez. o meu passado, sei lá” (E 3).

Reconhecimento do Consumo Abusivo. Apenas um dos entrevistados negou o consumo do álcool. Os outros quatorze andarilhos (93,3\%) assumiram a ingestão freqüente de bebidas alcoólicas, negando, porém, o consumo abusivo. Tais sujeitos afirmam categoricamente que possuem controle absoluto sobre o álcool e que são capazes de parar de beber no momento que desejarem:

"Se eu quisé eu bebo hoje, se eu não quisé, amanhã eu não bebo. Eu sou um camarada independente, nada me contamina, cara. Eu faço aquilo que eu quero" (E 4).

A análise dos temas emergentes no TÓPICO 4 (Relações afetivas) permitiu uma divisão em 3 categorias:

Relacionamentos Afetivos Antes do "Trecho". Treze andarilhos (86,6 \%) afirmaram que, antes do "trecho", viveram experiências afetivas relativamente estáveis. A maior parte destes relacionamentos gerou filhos e não foi legitimizada religiosa e/ou civilmente. De forma geral, foi feito um balanço positivo destas experiências, apesar do reconhecimento da existência de algumas 
dificuldades, como ciúme e infidelidade (ver categoria seguinte):

"Fui amasiado várias vezes... não posso negar que tive momentos felizes. Com todas elas en tive momentos felizes. Tive momentos tristes, passemos por dificuldades de todas as formas, mas teve momentos felizes, muito felizes" (E 3).

Desilusões Amorosas. Histórias de relacionamentos afetivos que foram mal-sucedidos e trouxeram sofrimento e desilusão foram relatados por onze andarilhos $(73,3 \%)$. O insucesso nessas experiências envolve uma complexa rede de causalidade múltipla, onde parecem ter exercido um papel mais determinante a traição e infidelidade, o ciúme e o uso excessivo de bebidas alcoólicas:

"Olha, desilusão en já tive umas trezentas vezes... saía briga por causa dessas coisa (ciúmes). O ciúme e a bebida tava sempre juntos" (E 1).

"Tá... já levei chifre de corno". (E 6)

Relacionamentos Afetivos no "Trecho". Contatos sexuais/ afetivos parecem ocorrer apenas esporadicamente no "trecho", geralmente com mulheres na mesma condição de errante e/ou em casas de prostituição nas estradas, segundo o relato de doze entrevistados $(80 \%)$ :

"É, arrumá mulher não é fácil. É bem difícil pra caramba. Você encontra trecheira, você começa a conversá com ela, talvez. dá, talvez não dáa...” (E 5).

"...é assim, só com muié de zona mesmo" (E 2).

\section{Discussão dos resultados}

As transformações sociais, políticas e econômicas da atualidade parecem exercer um papel determinante na desterritorialização dos sujeitos e na impulsão para o nomadismo, segundo o depoimento de 53,3\% dos indivíduos (oito andarilhos). O desemprego, decorrente da crescente exigência de qualificação, praticamente impossibilita os sujeitos com pouca capacitação de competirem no mercado de trabalho, estigmatizando, excluindo e marginalizando os indivíduos desprovidos de uma ocupação. No entanto, a deficiência de qualificação não é o único fator que contribui para as altas taxas de desemprego dos tempos atuais. Mesmo que todos os trabalhadores atualmente desempregados procurassem obter melhor qualificação e formação profissional, continuaria havendo um excedente de mão-de-obra disponível no mercado, pois como afirmou Castel (1998), no mundo contemporâneo há um déficit de lugares ocupáveis na estrutura social. $\mathrm{O}$ desemprego, segundo Singer (1999), é inerente ao capitalismo, e revela, de acordo com Castel (1998, p. 511) "o calcanhar-de-Aquíles do Estado social dos anos de crescimento".

Os "trecheiros", dessa forma, podem ser considerados, segundo a terminologia proposta por
Castel (1998), como "sobrantes e inadaptados sociais", por não conseguirem acompanhar a dinâmica da sociedade capitalista salarial e viverem "sob o signo da inutilidade social", impossibilitando a inscrição nas coerções da atual conjuntura econômica e em estruturas sociais portadoras de sentido. Assim sendo, vivem marginalizados, à beira de um abismo social, o que causa um impacto psicológico severo e intenso, pois, segundo Melman (1992), o sentimento de pertinência a uma categoria social, independente de qual seja, é indispensável para o bom funcionamento mental de um sujeito.

A vida dos andarilhos, segundo o relato de onze deles $(73,4 \%)$, pareceu marcada, desde a infância e adolescência, por conflitos e divergências no seio familiar. Oriundos de famílias com baixo poder aquisitivo, as relações entre os entes dos entrevistados foram, na maioria dos casos, permeadas por discussões e desentendimentos. Estes conflitos podem ter gerado fissuras na organização familiar e contribuído, juntamente com outros fatores, para a deserção, visto que, de acordo com Snow e Anderson (1998), as desavenças familiares são um dos fatores preponderantes para o rompimento do sujeito com o nicho social no qual está inserido.

No que diz respeito aos processos de ruptura com a vida sedentária, oito entrevistados $(53,3 \%)$ relataram que a morte dos pais exerceu um papel determinante, impulsionando-os para a deserção. A perda dos familiares, não há dúvida, é um acontecimento desestruturante, mas que atuou nos entrevistados como força motivadora da decisão de "correr o trecho" somente em conjunto com outros eventos, tais como a crescente pauperização decorrente do desemprego.

Neste ponto parece que a falta de apoio dos familiares atua como um elemento a mais enredando essa intrincada situação, visto que treze entrevistados (86,6 \%) relataram que os conflitos familiares, tanto com os pais no núcleo familiar originário quanto com a esposa ou filhos, também exerceram um papel importante na ruptura com a vida sedentária. O sujeito, desempregado, sem dinheiro e vitimado pelo corte de benefícios, não encontrando na família o suporte emocional de que necessita, fica ainda mais desestruturado. Intimamente ligado ao desemprego está o aumento da pobreza e as cobranças sociais, que pressionam o indivíduo a arcar com o ônus da vida sedentária, tais como contas a pagar, despesas domésticas, aluguel, etc., tornando a situação insustentável e impulsionando o sujeito à deserção e à errância.

A vida errante pode ser considerada, nesse contexto, como uma resposta radical a essa diversidade de problemas relatados; como uma tentativa de fugir da sociedade (Merton, 1968, apud Snow \& Anderson, 
1998). A maior parte dos entrevistados, ao que tudo indica, não "optou" pelo "trecho" por livre e espontânea vontade, e sim foi levada a essa condição de vida por fatores que fugiram a seu controle. Dessa forma, é possível pensar, assim como Castel (1998), que o caráter errático da trajetória de vida dos andarilhos não é decorrente apenas de fatores individuais de inadaptação.

No "trecho", o andarilho dificilmente se insere em algum tipo de coletividade. A ausência de vínculos e referenciais estáveis o conduz a um individualismo exacerbado e veemente, de modo que as normas sociais de conduta são colocadas em segundo plano, visto que o que prevalece, na realidade, é o "cada um por si".

A condição de errante parece implantar na existência dos sujeitos pesquisados um sentimento constante de incerteza, decorrente da precariedade e desassistência características desse modo de vida. A busca pela sobrevivência é contínua e incessante, o que torna o cotidiano sofrível e desgastante, tanto física quanto mentalmente. A insuportabilidade da vida nômade tornase mais evidente considerando-se que doze sujeitos (80 $\%$ deles) afirmam que não há vantagem alguma nessa forma de vida. Assim sendo, retornar ao sedentarismo e aos referenciais estáveis de fixações sociais, geográficas e afetivas constitui o maior desejo de 93,3\% dos entrevistados (quatorze andarilhos). Muitos deles, no entanto, parecem não acreditar nesse retorno, principalmente em virtude da falta de perspectivas. Os resultados dos trabalhos de Snow e Anderson (1998) e Justo (1998) com populações marginalizadas e itinerantes também apontam nessa direção.

A despeito de ser um dos traços definidores do estilo de vida atual dos andarilhos, o álcool, segundo os depoimentos coletados, já se fazia presente desde a infância dos sujeitos, graças à influência dos pais ou familiares. O estímulo dos amigos também exerceu um importante papel no início do consumo de bebidas alcoólicas, pois as condutas etílicas eram vistas como uma forma de mostrar masculinidade e garantir a inserção no grupo social desejado. Os dados encontrados na literatura especializada confirmam que tais influências costumam ser as mais operantes na origem da dependência etílica (Araújo, 1995; Silva \& Cursino, 1995; Sonenreich, 1971).

Já no "trecho", os motivos apresentados pelos entrevistados como sendo responsáveis pelo consumo de álcool são, basicamente, a necessidade de esquecer problemas do passado e adquirir um maior encorajamento para enfrentar a precariedade, o isolamento e a solidão da errância. $\mathrm{O}$ uso do álcool significaria, assim, uma possibilidade de evasão da realidade, já que esta é vivenciada com sofrimento e dificuldades, permeada por um sentimento quase constante de solidão insuportável, desesperança e carência vivencial. A bebida criaria, nesses termos, determinadas condições emocionais, tais como a desenvoltura e a desinibição, mais favoráveis à mendicância, visto que esse é um dos recursos utilizados para a obtenção da subsistência. Se a existência dos andarilhos pesquisados é por eles vivenciada de forma sofrida e consternada, como foi possível detectar na análise das entrevistas, a embriaguez lhes permite "esquecer" todo esse sofrimento, representando, assim, uma grande possibilidade de alívio, trazendo uma felicidade efêmera baseada na idéia errônea de que é possível obter com o álcool uma satisfação plena e absoluta (Melman, 1993).

Dentre os quinze entrevistados, quatorze deles (93,3 $\%$, admitem a utilização constante de bebidas alcoólicas. No entanto, doze sujeitos $(85,7 \%$ dos que reconhecem o consumo etílico) negaram o uso abusivo e a dependência e acreditam que são capazes de parar de beber quando for da sua vontade. Sabe-se, porém, que a insinceridade é um mecanismo de defesa freqüente entre os alcoolistas (Van Kolck, Tosi e Pellegrini, 1991), principalmente porque o "outro" é percebido, na maioria das situações, como ameaçador (Alonzo-Fernández, 1991). O uso constante da bebida prejudica o juízo de realidade, e faz com que o alcoolista desenvolva uma postura de constante defesa diante dos que o desafiam ou contrariam, de modo que, muitas vezes, o indivíduo etílico-dependente consegue inventar pretextos e mentir com extrema naturalidade, o que torna difícil a um interlocutor distinguir o que é ou não verídico (Lopes, 1976).

No que diz respeito aos relacionamentos afetivos, treze entrevistados, ou seja, 86,6\% deles, afirmaram que possuíam vínculos relativamente estáveis e significativos antes do "trecho". Muitos eram "amasiados" ou possuíam parceiras fixas e filhos, que foram abandonados quando do rompimento com a vida sedentária. Segundo o relato dos mesmos, esses relacionamentos foram satisfatórios, apesar de permeados por conflitos, desavenças, ciúme e traições. Uma parcela significativa dos andarilhos pesquisados (73,3\% dos sujeitos, isto é, onze deles) afirmou ter sofrido desilusões amorosas que envolveram a infidelidade conjugal, e isso parece ter sido um evento tão perturbador a ponto de impulsioná-los para o nomadismo. É relevante enfatizar novamente que, de acordo com os dados obtidos, um acontecimento isolado por si só não parece ser suficientemente desestruturante a ponto de levar o sujeito a se agregar aos que vagam sem destino pelas estradas. Assim sendo, as desilusões amorosas decorrentes da traição conjugal e infidelidade podem ser consideradas como uma das forças motivadoras capazes de levar um indivíduo a 
abandonar as fixações sociais e geográficas somente se associadas a outras forças igualmente intensas.

As aspirações futuras de 93,3\% andarilhos (quatorze sujeitos) estão relacionadas ao sonho de retornar ao sedentarismo, readquirir um emprego, construir uma casa própria e constituir uma família. No entanto, esse desejo parece distante e inexeqüível, de forma que treze deles (92,9 \% dos que manifestaram esta aspiração) não acreditam com convicção nessa possibilidade, condicionando a realização desse sonho à ajuda redentora e milagrosa de terceiros, ao invés de dar crédito às próprias forças e potencialidades.

Faz-se necessário reconhecer que o relato verbal dos andarilhos pesquisados foi marcado por uma série de mecanismos de defesa, tais como a insinceridade, a tendência a fazer-se de vítima no contato com o interlocutor, as queixas de insuportabilidade da condição atual e a propensão a atribuir a terceiros a responsabilidade de acontecimentos em sua vida que seriam, na realidade, de sua única e exclusiva alçada. Dessa forma, as considerações até aqui apresentadas foram elaboradas levando-se em conta essa ressalva.

\section{Conclusão}

Como conclusão dos resultados obtidos no presente trabalho, pode-se afirmar que a errância é um fenômeno complexo e multifatorial, intimamente ligado a algumas das principais características que modelam o mundo contemporâneo, tais como as constantes transformações políticas e econômicas, a globalização, a precarização das relações de trabalho, o desemprego, a exclusão social, a necessidade de uma mobilidade psicológica capaz de permitir uma rápida adaptação a paradigmas em incessante metamorfose, o caráter cada vez mais efêmero dos relacionamentos afetivos e emocionais e das fixações sociais e geográficas, dentre outras.

Tendo em vista os objetivos inicialmente estabelecidos, o contato com os andarilhos pesquisados indica que a maioria deles é originária de familias nas quais divergências e conflitos, motivados por inúmeros fatores, eram freqüentes, gerando a desestruturação da organização familiar e impulsionando o rompimento com esse nicho. Os motivos que os levaram à condição de nômades errantes possuem íntima ligação entre si e podem ser classificados basicamente em dois planos: psicológico (morte dos pais, conflitos familiares diversos e infidelidade conjugal) e socioeconômico (desemprego e pauperização). Dessa forma, os andarilhos não "optaram" por essa situação na qual se encontram atualmente, e sim foram levados por forças maiores, que não puderam ser controladas.

O cotidiano dos andarilhos pesquisados é permeado por um sentimento constante de incerteza, decorrente do isolamento e da precariedade dessa condição, que instala o provisório como modo de existência. $\mathrm{O}$ estilo de vida desses sujeitos é baseado na tríade bebida, migração e eventuais trabalhos. A subsistência é árdua e imprevisível, obtida através de trabalhos esporádicos e/ou mendicância. O uso do álcool no "trecho" é constante, generalizado e associado principalmente à necessidade de esquecer problemas do passado, de adquirir maior encorajamento para enfrentar as condições de vida adversas e de evasão da realidade penosa e da carência vivencial. A bebida alcoólica representa, dessa forma, uma grande possibilidade de alívio, baseando-se na idéia equivocada de que a intoxicação etílica é capaz de trazer uma satisfação plena e absoluta.

Os vínculos no "trecho" são superficiais e provisórios, visto que os andarilhos geralmente não desejam se inserir em espécie alguma de coletividade e preferem a solidão e o isolamento. A desconfiança e insegurança dominam esse universo; o que os leva a caminhar sozinhos pelos acostamentos das estradas, não se apegando a nada e nem a ninguém. A ausência de vínculos e de referenciais estáveis ligados às malhas $\mathrm{da}$ rede social os torna altamente individualizados e, como conseqüência, superexpostos e vulneráveis. $\mathrm{O}$ desejo de retornar à vida sedentária, conseguir um emprego, constituir uma família e um lar foram relatados como os grandes sonhos dos entrevistados. No entanto, há o reconhecimento de que a atual condição de vida oferece poucas oportunidades para a concretização dessas aspirações. Desse modo, os andarilhos são levados a acreditar que esses sonhos e desejos talvez nunca se tornem realidade.

\section{Referências Bibliográficas}

Alonzo-Fernández, F. (1991). A personalidade prealcoólica (L. M. N. Terroni, Trad.). Temas, 21 (40/41), p. 19-30.

Araújo, L. B. (1995). O uso do álcool como ritual de passagem da adolescência para a idade adulta: alguns aspectos indicativos para programas de prevenção ao abuso do álcool. [Resumos] Em: Sociedade Brasileira de Psicologia (Org.) Anais, XXV Reunião Anual de Psicologia (p.41). Ribeirão Preto, SP, SBP.

Bardin, L. (1979). Análise de conteúdo (L.A. Reto \& A. Pinheiro, Trad.). Lisboa: Edições 70.

Castel, R. (1998). As metamorfoses da questão social: uma crônica do salário (I. D. Poletti, Trad.). Petrópolis, RJ: Vozes.

Castro, H. M. \& Silva Filho, W. M. (1993). Avaliação do programa de atenção ao alcoolista no município de Carapicuíba. Temas, 23 (46), p. 141-175.

Jacques, M. G. C. (1998). Identidade e trabalho: uma associação indispensável. Em: A. Tamayo; J. E. Borges- 
Andrade \& W. Codo (Orgs.) Trabalho, organizações e cultura. (p. 41-47) São Paulo, SP: Cooperativa de Autores Associados.

Justo, J. S. (1998). Errância e errantes: um estudo sobre os andarilhos de estrada. Em: J. S. Justo \& R. Y. Sagawa (Orgs.) Rumos do saber psicológico (p. 125-139). São Paulo, SP: Arte \& Ciência.

Lopes, R. T. (1976). Comportamento do alcoólatra. Em: S.S. Moutinho (Org.) Temas de alcoolismo (p. 35-39). São Paulo, SP: Manole.

Melman, C. (1992). Alcoolismo, delinqüência e toxicomania: uma outra forma de gozar. (R. Pereira, Trad.). São Paulo, SP: Escuta.

Melman, C. (1993). Alcoolismo e toxicomania: uma abordagem psicanalítica. (L.C.A. Alves, Trad.) Temas, 23 (45), p. 41-49.

Ministério da Saúde (1996). Resolução no. 196/96 sobre pesquisas envolvendo seres humanos. Brasília, DF: Conselho Nacional de Saúde.

Nascimento, E. C. (1999). Vidas errantes e alcoolismo: estudo das relações entre o uso de bebidas alcoólicas e a errância [Resumos]. Em: Universidade Estadual Paulista (Org.), Anais, XI Congresso de Iniciação Cientifica da UNESP (p. 143). Presidente Prudente, SP: UNESP.

Nascimento, E. C. \& Justo, J. S. (2000). Vidas errantes e alcoolismo: uma questão social. Psicologia: Reflexão e Crítica,
13 (3), p. 529-538.

Pittman, D. (1994). Mentiras privadas: a infidelidade e a traição da intimidade. (M. A. V. Veronese, Trad.). Porto Alegre, RS: Artes Médicas.

Silva, R. C. \& Cursino, E. A. (1995). O consumo de bebidas alcoólicas por adolescentes: dados sobre o consumo e concepções sobre o uso. [Resumos] Em: Sociedade Brasileira de Psicologia (Org.), Anais, XXV Reunião Anual de Psicologia (p.179). Ribeirão Preto, SP: S.B.P.

Singer, P. (1999). Globalização e desemprego: diagnóstico e alternativas. São Paulo, SP: Contexto.

Snow, D. \& Anderson, L. (1998). Desafortunados: um estudo sobre o povo da rua (S. Vasconcelos, Trad.) Petrópolis, RJ: Vozes.

Sonenreich, C. (1971). Contribuições para o estudo da etiologia do alcoolismo. Tese de Doutorado. Faculdade de Medicina, Universidade de São Paulo, São Paulo, SP.

Van Kolck, O. L.; Tosi, S. M. V. D.; Pellegrini, T. F. (1991). Auto-imagem em alcoólicos crônicos. Temas, 21 (42), p. 374-382.

Recebido em 21/09/2000

Revisado em16/05/2001

Aceito em 21/06/2001

Sobre o autor:

Rodrigo Sanches Peres é Graduando do curso de Psicologia da UNESP/Assis, dedica-se à clínica de orientação psicanalítica e à produção científica, atualmente com um estudo da personalidade de andarilhos subsidiado pela FAPESP. 